\title{
Convergencia contable de las PyME colombianas
}

\author{
Convergence of Accounting Standards among Colombian SMEs \\ Convergência contábil das PMEs colombianas
}

Carlos Jair Ruano Delgado

Universidad de San Buenaventura, Colombia

ORCID: http://orcid.org/0000-0003-2084-350X

DOI: https://doi.org/10.11144/Javeriana.cc19-47.ccpc Redalyc: http://www.redalyc.org/articulo.oa?

Carlos Arturo Vargas Sierra

Universidad de San Buenaventura, Colombia

ORCID: http://orcid.org/0000-0003-4656-7371

Fecha de recepción: 28 Noviembre 2017 Fecha de aprobación: 12 Junio 2018

Guiovanny Lasso Marmolejo

Universidad de San Buenaventura, Colombia

ORCID: http://orcid.org/0000-0003-1969-7461

\section{Resumen:}

Usando una muestra de pequeñas y medianas empresas colombianas, investigamos el efecto del proceso de convergencia contable sobre dieciséis factores contables yfinancieros, para el cierre de 2015. En el presente artículo se analiza la significancia estadística de las variaciones de la información contable presentada bajo la normatividad contable colombiana y las normas internacionales de información financiera (NIIF). Observamos, en términos generales, que se presentan efectos cuantitativos significativos para los factores analizados, excepto para el retorno sobre el patrimonio. Hallamos, igualmente, que los efectos del proceso de convergencia contable mantienen su significancia cuando se observa su sensibilidad a la actividad económica desempeñada por la empresa y el tipo de sociedad constituida; y no lo son cuando se analizan los resultados respecto del tamaño y la antigüedad empresarial.

Palabras clave: convergencia contable, NIIF, PyME.

\section{Abstract:}

Using a Small and Medium-Sized Enterprises (SMEs) sample from Colombia, we conducted a research regarding the effect of the convergence-of-accounting-standards process on sixteen accounting and financial factors for 2015 year-end closing. This article examines the statistical significance of the variations in the accounting information submitted under both the Colombian accounting regulations and the International Financial Reporting Standards (IFRS). In general, we observed some significant quantitative effects occurring in the factors under study, except for the Return On Equity. Likewise we found that the effects of the said convergence process remain significant when looking at their sensitivity to the type of business developed by the company and the type of partnership they incorporated. The effects are not significant when examining the results related to the company size and the business age.

Keywords: convergence of accounting standards, IFRS, SMEs.

\section{Resumo:}

Usando uma amostra de pequenas e médias empresas colombianas, pesquisamos o efeito do processo de convergência contábil sobre dezesseis fatores contábeis e financeiros, para o fechamento de 2015. No presente artigo é analisada a significância estatística das mudanças nas informações contabilísticas apresentadas sob o Regulamento contábil colombiano e as normas internacionais de informação financeira (IFRS). Observamos, em termos gerais, que efeitos quantitativos significativos para os fatores analisados são apresentados, com exceção para o retorno sobre o patrimônio líquido. Achamos, igualmente, que os efeitos do processo de convergência contábil mantem a significância quando observada sua sensibilidade à atividade económica exercida pela empresa e o tipo de sociedade constituída; e não quando analisados os resultados no que diz respeito do comprimento e a antiguidade empresarial.

Palavras-chave: convergência contábil, NIIF, PMEs. 


\section{Introducción}

Colombia asumió el proceso de armonización de sus principios contables hacia las Normas Internacionales de Información Financiera (NIIF) con la promulgación de la Ley 1314 de 2009, cuyo objetivo primordial es conformar un sistema único y homogéneo de alta calidad, comprensible y de forzosa observancia por quienes reportan información contable-financiera. El Consejo Técnico de la Contaduría Pública (CTCP), como órgano técnico delegado del proceso de convergencia contable, presentó las consideraciones necesarias para tal fin, a partir de las cuales el gobierno nacional expidió los decretos reglamentarios que señalaban, entre otros aspectos, la clasificación de las empresas en tres grupos, cada uno de los cuales asumiría la convergencia contable con sus particularidades para el reporte de información financiera.

Acorde con el direccionamiento señalado por el CTCP (2012), el grupo 1 está constituido por empresas que cumplen las condiciones de ser: a) emisores de valores; b) entidades de interés público; $c$ ) entidades con activos superiores a 30000 salarios mínimos mensuales legales vigentes ( $\mathrm{Smmlv}$ ), o que posean más de 200 empleados, que no sean emisores de valores ni entidades de interés público y que cumplan adicionalmente con lo siguiente: 1 . ser subordinada o sucursal de una compañía extranjera que aplique las NIIF; 2 . ser subordinada o matriz de una compañía nacional que deba aplicar las NIIF; 3. realizar importaciones o exportaciones que representen más del $50 \%$ de las compras o de las ventas, respectivamente, del año gravable inmediatamente anterior al ejercicio sobre el que se informa, o 4. ser matriz, asociada o negocio conjunto de una o más entidades extranjeras que apliquen las NIIF.

Por otra parte, en el grupo 2 se incluyen empresas: 1) que no cumplen con lo establecido en el literal c) del grupo 1;2) que tengan activos totales por valor entre 500 y 30000 Smmlv, o una planta de personal entre 11 y 200 trabajadores, y que no sean emisores de valores ni entidades de interés público; 3) microempresas que tengan activos totales, excluida la vivienda, por un valor máximo de $500 \mathrm{Smmlv}$ o planta de personal no superior a los diez trabajadores, y cuyos ingresos brutos anuales sean iguales o superiores a $6000 \mathrm{Smmlv}$.

El grupo 3 está conformado por: 1) personas naturales o jurídicas que cumplan los criterios establecidos en el Artículo 499 del Estatuto Tributario; 2) microempresas que tengan activos totales, excluida la vivienda, por un valor máximo de $500 \mathrm{Smmlv}$ o planta de personal no superior a los 10 trabajadores y que no cumplan con los requisitos para ser incluidas en el grupo 2 ni en el literal anterior.

En la investigación que se desarrolla, el alcance está limitado al grupo 2, conformado por las pequeñas y medianas empresas (PyME), tomando en consideración sus características empresariales y su importancia dentro de la economía local. El International Accounting Standards Board (IASB) señala que las NIIF para PyME (IASB, 2009) son un estándar autónomo, menos complejo que las NIIF plenas, organizado por tópicos, acoplado y enfocado en las necesidades de información de los usuarios de los estados financieros de las PyME, quienes requieren principalmente de información sobre flujos de efectivo, liquidez y solvencia.

Por otro lado, el estándar toma en consideración los costos y las capacidades de este tipo de empresa para preparar información financiera y presenta simplificaciones en los siguientes asuntos: 1. tópicos no relevantes para las PyME son omitidos; 2. algunos principios para el reconocimiento y medición de activos, pasivos, ingresos y gastos son simplificados, y 3 . significativamente menos revelaciones son requeridas.

En el Decreto 3022 de 2013, el Estado colombiano estableció que el grupo 2 se acogiese a las NIIF para PyME, definiendo que PyME son: 1. entes económicos con activos entre 501 y $30000 \mathrm{Smmlv}$ o planta de trabajadores entre 11 y 200 trabajadores; 2 . microempresas que tengas activos, excluida la vivienda, máximo de 500 Smmlv y planta de personal no superior a 10 trabajadores. La convergencia contable de las PyME contó con actividades de apoyo y orientación por parte de la Superintendencia de Sociedades (SS) y el CTCP a lo largo del calendario establecido para esta, el cual señaló que para el año 2015 se debería construir el Estado de Situación Financiera de Apertura (ESFA) y se reportaría al cierre de ese año de transición la información de los estados financieros paralelamente bajo principios contables locales y bajo las NIIF para PyME. 
El propósito de este artículo es analizar el efecto del proceso de convergencia contable sobre la información contable-financiera de las PyME colombianas, al cierre del periodo de transición. Para llevar a cabo la investigación se construyó una muestra relacionada y pareada de empresas PyME que reportaron información contable a la SS, para el cierre del año 2015. La comparación pareada o directa puede llevarse a cabo toda vez que las empresas seleccionadas en la muestra reportaron sus estados financieros a la SS bajo la norma local y bajo las NIIF. Específicamente, se investigaron los efectos sobre factores contable-financieros seleccionados, a partir del análisis de su significancia estadística, en primera instancia de manera global, realizando luego un análisis de sensibilidad de los efectos encontrados a partir de parámetros de actividad económica, tamaño, tipo de sociedad constituida y años de constitución de las empresas de la muestra. Trabajar con una muestra relacionada y pareada permite encontrar el efecto directo del proceso de convergencia para cada empresa que compone la muestra, posibilitando el posterior análisis de dicho proceso por sector, tamaño y tipo de empresa.

En el desarrollo del artículo se realiza una revisión bibliográfica de estudios realizados en Europa, América Latina y Colombia sobre los efectos de adopción o convergencia contable en la información contablefinanciera empresarial; en una segunda instancia se expone la metodología de investigación, presentando la selección de la muestra objeto de estudio y la hipótesis de trabajo. Un siguiente apartado presenta los resultados obtenidos, en término general y por particularidades de interés de los autores. Se termina con el aparte de las conclusiones acerca de la investigación llevada a cabo.

\section{Revisión de literatura}

El proceso de adopción o convergencia contable hacia las NIIF ha sido llevado a cabo por más de un centenar de países en el contexto mundial, y sus efectos en la información contable y financiera de las empresas han sido objeto de diversos estudios. Aquí se retoman algunos casos internacionales y locales, en primera instancia para el proceso de adopción de las NIIF plenas, y se presentan luego casos relacionados con la implementación de las NIIF para PyME.

Callao, Ferrer, Jarne y Laínez (2010, p. 4) estudian el impacto de las NIIF en algunas variables contables financieras para empresas listadas en el Índice General Bursátil de Madrid (IGBM), de España y el Financial Times Stock Exchange Index 100 (FTSE), del Reino Unido, encontrando que el impacto cuantitativo sobre ellas es significativo en ambos países; observan que las NIIF tienen un efecto negativo sobre la relevancia de los informes financieros en ambos países, siendo significativo solo para España. La investigación de Lueg, Punda y Burkert (2014) encuentra diferencias sustanciales en los indicadores financieros, en la transición a las NIIF, en empresas listadas del Reino Unido, hallando que las medianas de estos se incrementan sustancialmente y que se presenta un aumento en las ganancias operacional y neta, y un decrecimiento en el patrimonio. El estudio de Perafán y Benavides (2017) retoma empresas cotizantes en los mercados de valores de Francia y Reino Unido, encontrando que para este último el tamaño empresarial influye en el impacto generado por las NIIF, mejorándose la información financiera después de la adopción; mientras que en Francia los resultados no soportan ninguna mejora en la calidad de la información.

El trabajo de Gassen y Sellhorn (2006) encuentra significantes diferencias en la calidad de las ganancias de las empresas alemanas, señalando que las que adoptaron las NIIF tiene ganancias más persistentes, menos predecibles y más conservadoras, y el precio de sus acciones parecen ser más volátiles. Por otra parte, Hung y Subramanyam (2007) muestran que el proceso de adopción de las NIIF por parte de empresas industriales alemanas posee impacto positivo sobre los activos totales y el valor en libros del patrimonio, atribuyendo esos cambios a los ajustes en el componente de propiedad, planta y equipos, reducción de provisiones, cambio en los inventarios y ajustes en los intangibles, señalando que el beneficio y el patrimonio en libros no son más relevantes bajo el marco internacional que bajo el marco local. 
La investigación de Elbakry, Nwachukwu, Abdou y Elshandidy (2017) analiza empresas alemanas y del Reino Unido listadas en sus mercados de valores, encontrando que, a pesar de la importancia del valor en libros, los valores de patrimonio han disminuido y han sido reemplazados por la creciente popularidad de los beneficios, tanto en Alemania como en el Reino Unido, después del cambio a las normas internacionales.

En España, Perramon y Amat (2006) toman empresas no cotizadas y señalan que la adopción de las NIIF puede influir en los resultados de las ganancias, y explican que la diferencia que ellas causan para la ganancia neta no depende de la tasa de ganancia y los activos totales de las compañías, sino que están relacionadas principalmente con la aplicación del valor razonable para los instrumentos financieros y las nuevas reglas para la contabilidad de la plusvalía. El trabajo de García y Moya (2009) toma empresas españolas cotizadas y analiza la influencia de las NIIF en la valoración de ellas, encontrando que la capacidad explicativa de la información bajo los sistemas local e internacional es similar y reconociendo que esto puede deberse a que su aplicación es reciente en el caso español. La investigación de Alvarado, Ampudia y Prado (2009) revisa el caso de grupos empresariales no financieros del IBEX 35 español, encontrando variación negativa del patrimonio neto en las empresas de la muestra, generado por los ajustes en diferentes rubros contables examinados. Por su parte, Marín, Antón y Ortiz (2015) retoman aspectos de la evolución del proceso de convergencia en España, en un lapso de seis años, destacando que fue el patrimonio de las empresas el que presentó los mayores cambios en el proceso.

En Latinoamérica se poseen trabajos enfocados en dos perspectivas: una centrada en la revisión del estado del proceso de adopción de las NIIF; otra encaminada a mostrar los efectos de ellas sobre algunos aspectos de la información contable-financiera.

El trabajo de Palacios y Martínez (2005) revisa las contribuciones al proceso de armonización aportados por el Grupo de Integración del Mercosur de Contabilidad, Economía y Administración (Gimcea), considerando los procedimientos y mecanismos incorporados por Argentina y Brasil; y también por el Comité para la Cooperación en Asuntos de Informes Financieros del Tratado de Libre Comercio de América del Norte (Tlcan), en el que se retoma las experiencias de Chile y México. Los autores encuentran que existen unas diferencias importantes entre las normas locales y las internacionales, pero señalan que se está realizando un esfuerzo por parte de los países para establecer estándares comunes de medición y presentación de la información financiera que permita transparencia y comparabilidad de la misma. La investigación llevada a cabo por Vílchez (2008) realiza una clasificación de los países latinos según el estado del proceso de adopción y convergencia hacia las NIIF, encontrando que la adopción ha sido el camino más optado y que en general la armonización contable está en una fase avanzada en algunos países.

El estudio de Molina, Díaz, Capuñay y Casinelli (2014) analiza el proceso de armonización contable en España, Perú y Argentina, señalando las características particulares de cada país en la evolución hacia la adopción de las NIIF. Por otra parte, Sarquis, Luccas y Lorenço (2014) realizan un trabajo de caracterización de los sistemas contables de cinco países latinoamericanos (Argentina, Brasil, Chile, México y Perú) después de la adopción de las NIIF, encontrando que los países analizados poseen características semejantes; señalan que Chile y Perú son los que presentan mayores similitudes, mientras que los restantes países se distancian un poco más. Carneiro, Rodrigues y Craig (2017) trabajan una muestra de trece países del Grupo latinoamericano de Emisores de Normas de Información Financiera (Glenif), estableciendo que varios de ellos han efectuado la adopción de las NIIF plenas, mientras que en otros no están admitidas. Los autores concluyen que la armonización contable será difícil de lograr, debido a que los sistemas de aplicación son poco confiables y a las lógicas institucionales competidoras de los sistemas tributarios, bancos y compañías de seguros existentes en cada país.

Tomando en consideración los efectos del proceso de adopción o convergencia en el contexto latinoamericano, el trabajo de Costa dos Santos y Nóbrega (2014) señala que las NIIF incrementan los beneficios contables y no poseen efectos sobre el postulado del conservadurismo contable para las compañías brasileñas que cotizan en bolsa. La investigación de Confetti, Da Silva, Ambrozinni y Guasti (2016) encuentra 
que la adopción de las normas internacionales no contribuyó a reducir el costo patrimonial de empresas de capital abierto en Brasil, mientras que el trabajo de Black y Hiroshi (2016) concluye que algunas compañías listadas en la Bolsa de Sao Pablo presentan relevancia del valor de ingresos netos y una menor gestión de los resultados después de la adopción de las NIIF. Menezes y Ciampaglia (2017) muestran que después de haberse adoptado las NIIF se incrementó la calidad de las ganancias empresariales en Brasil, además de que el costo de capital propio se redujo después de la adopción total de las normas.

La investigación de Yáñez, Pilar e Inostrosa (2010) analiza la implementación de las NIIF en dieciséis empresas chilenas cotizadas en la Bolsa de Santiago, en el año 2008, mostrando su efecto patrimonial, y señala que la dificultad de su aplicación está en la determinación del valor razonable para cada partida del activo y del pasivo. Por otra parte, Jara, Contreras y Castro (2010), con una muestra de dieciocho empresas chilenas cotizadas del sector eléctrico, encuentran que la aplicación de las NIC 16 y 39 son las más relevantes en los efectos generados en la información contable, al adoptar las normas internacionales.

En el trabajo llevado a cabo por Vásquez (2012) se retoma a empresas listadas en la Bolsa Mexicana de Valores (BMV) y analiza la variación en las medianas de algunas razones financieras y cuentas contables en el año 2012, encontrando que no hay diferencias estadísticas significativas en ellas al tomar en consideración las NIIF y las normas locales mexicanas. Señala el autor que los principales ajustes patrimoniales se deben al uso del modelo de revaluación aplicado a la propiedad, planta y equipo (PPE). Por otra parte, Garza, Cortez, Méndez y Rodríguez (2017) estudian la relevancia valorativa de la información financiera de 141 empresas mexicanas que cotizan en BMV, en el período 2000-2013, encontrando que las NIIF aumentan la relevancia valorativa y logran que la información sea más confiable

Los trabajos de Rathke y Santana (2015), Silva, Pletsch, Klann, Fasolin, Scarpin y Major (2015) y Rathke, Santana, Lorenço y Dalmácio (2016) analizan la influencia de la convergencia contable sobre la gestión de los resultados en empresas latinoamericanas. El trabajo de Rathke (2015) compara el nivel de gestión de los resultados en Brasil, Chile y Perú, encontrando que este presenta diferentes niveles antes de la adopción de las NIIF, pero que esas diferencias no se mantienen después de la adopción, e indicando que las normas internacionales hacen que la información sea más homogénea, mejorando de ese modo la comparabilidad de la información de las empresas latinoamericanas.

Silva et al. (2015) estudian empresas de Brasil y Chile, y encuentran que la adopción de las NIIF contribuyó a la reducción de las acumulaciones discrecionales y, por lo tanto, a la gestión de los resultados, aunque este efecto fue significativo solo en las empresas chilenas. La investigación de Rathke et al. (2016) compara la gestión de resultados de empresas en Brasil y Chile con la llevada a cabo en Reino Unido, Australia, Francia y Alemania, hallando que las latinoamericanas presentan un mayor nivel de gestión de resultados, y concluyen que incluso con un estándar único contable, las características específicas de cada país siguen desempeñando un papel relevante en la forma como las NIIF se implementan en cada uno de ellos.

Tomando una muestra de 923 empresas de Argentina, Brasil, Chile y México, el trabajo de Rodríguez, Cortez, Méndez y Garza (2017) señala que la calidad de la contabilidad se incrementa con la adopción de las NIIF, principalmente en las empresas grandes de Brasil, Chile y México, pero no en Argentina. Se logra establecer que existen efectos relevantes al introducir las NIIF, y que son más sólidos cuando se tienen mayores niveles de capitalización en las empresas. Por otro lado, la investigación de Polo, Palacios y Martínez (2015) analiza la adaptación de las normas locales de México a las NIIF, y encuentra que se ha incrementado la comparabilidad del resultado contable respecto a los principios contables de Estados Unidos, si bien ello se debe al uso oportunista que se hicieron de los métodos contables.

En el contexto nacional, el impacto del proceso de convergencia contable en el sector real de la economía ha sido analizado por la Superintendencia de Sociedades (SS, 2011; SS, 2012) desde una perspectiva de pronóstico, señalando el impacto patrimonial negativo que tendría el proceso de convergencia; destaca el efecto negativo de las cuentas de deudores, inventarios y PPE. Así mismo, estos estudios muestran que el impacto sobre las ganancias tendría carácter positivo, tanto para las grandes empresas como para las PyME. 
Ambos estudios se hacen a nivel de secciones económicas en el sector real de la economía, mostrando diferentes resultados para cada una de ellas, situación que la SS explica a partir de la naturaleza de las actividades empresariales.

En el trabajo del 2012, la SS utiliza los modelos del costo y del valor razonable para hacer el estudio de los dos grupos de empresas, grupo 1: empresas que aplicarían las NIIF plenas, y grupo 2: empresas que optarían por las NIIF para PyME.

La SS (2015) presentó los resultados parciales del proceso de convergencia para los grupos 1 y 2 , señalando que en el grupo 1 se dio una revaluación de los activos y un impacto negativo en el patrimonio; así mismo, se presentó un incremento en las ganancias del período 2014. Los resultados del grupo 2 muestran un deterioro patrimonial general, aunque algunas empresas reportan no variaciones en esta cuenta y otras muestran cambios positivos en el patrimonio. La SS señala que el mayor impacto en el activo de las empresas se da por tomar la revaluación como costo atribuido, y en el pasivo, por el impuesto diferido que se generó.

El análisis llevado a cabo por Católico, Cely y Pulido (2013) sobre el grado de revelación de la información contable presentado por empresas industriales cotizantes en la Bolsa de Valores de Colombia (BVC), para la cuenta de la PPE señala que este es bajo con respecto del solicitado por los requisitos definidos por las NIIF, toda vez que las empresas no presentan los detalles de la información asociada con la medición posterior, a los hechos posteriores o partidas específicas. La investigación de Londoño (2015) analiza aspectos del proceso de convergencia relacionados con la PPE y algunos indicadores financieros para PyME de diferentes sectores económicos, encontrando que la PPE y el patrimonio poseen variaciones diferentes en las empresas analizadas, así como sus indicadores financieros.

Por otra parte, Rendón, Rodríguez y Riascos (2013) llevan a cabo un estudio de carácter exploratorio con 18 entidades cooperativas del Valle, acerca del efecto del proceso de convergencia contable sobre las aportaciones de los asociados, que deberán ser ajustadas del patrimonio al pasivo, concluyendo que las cooperativas deben fortalecer su capital propio para que bajo las NIIF su estructura financiera involucre un mayor porcentaje en el patrimonio.

Para el caso de las PyME, el proceso de convergencia contable está enmarcado por las disposiciones señaladas en las NIIF para PyME, que son un marco diseñado para cumplir con informes financieros de empresas que: a) no tienen responsabilidad pública; b) presentan estados financieros de propósito general para usuarios externos (IASB, 2009). En el contexto nacional, las PyME representan un importante eslabón en la economía colombiana, desde la perspectiva de su participación en el número de establecimientos, hasta en la connotación de su aporte al mercado laboral nacional (Montoya, Montoya y Castellanos, 2010; INCP, 2017; ANIF, 2017).

El proceso de armonización contable que han aplicado las PyME en el contexto internacional se ha abordado marcadamente desde la perspectiva cualitativa de sus efectos e impactos. En el ámbito europeo, la dirección general para el Mercado Interno y los Servicios de la Comisión Europea (CE) presentó un informe para el cual consultó, en el año 2010, la opinión de las partes interesadas en 26 países miembros de la Unión Europea (UE), acerca del marco de las NIIF para PyME (CE, 2010), encontrando diversas opiniones con respecto a la potencial aplicación de ese marco; en particular, que la relación de normas impositivas de ciertos Estados de la Unión podría hacer que la implementación de las NIIF para PyME generara más costos para algunas empresas, al duplicarse los requisitos en la presentación de los informes financieros.

El informe señala posturas positivas sobre el nuevo marco, dadas por empresas con subsidiarias en otros Estados de la Unión o por empresas que buscan financiamiento internacional. Varios de los participantes del estudio expresaron que el uso del nuevo marco beneficiaría a los usuarios de la información, toda vez que se tendría una mayor capacidad para analizar y comparar los estados financieros, y así se podría lograr un mayor crecimiento de las empresas, una mayor generación de fusiones y adquisiciones de compañías, así como la reducción del costo de capital. 
Las opiniones adversas a la aplicación de las NIIF para PyME destacan que para las pequeñas empresas el marco puede ser complejo, y los costos de su implementación pueden superar sus beneficios. Los resultados de este informe son analizados por Quagli y Paoloni (2012), y enfocándose en la homogeneidad de las respuestas descubren que los preparadores de información demuestran que hay una oposición fuerte a las IFRS para PyME, mientras que la de los usuarios es favorable. Los países de ascendencia germana y latina muestra menos aprecio hacia este marco que los países anglos y nórdicos. Según los autores, esto conlleva consecuencias relevantes para la política pública europea.

El trabajo llevado a cabo por Bohusova (2011) expone, con un análisis cualitativo, que la presentación de informes financieros para las PyME bajo un solo marco normativo es un paso importante hacia la coherencia, la comparabilidad y la relevancia de la información entre las empresas de la UE; señala que el marco diseñado por las NIIF para PyME es más corto y claro que varios de los Principios contables generalmente aceptados de varios de los Estados miembros de la UE, por lo cual ese marco es la mejor solución para la armonización contable europea.

Por otra parte, el artículo de Baldarelli, Demartini, Monsja-Shake y Paoloni (2012) da cuenta de las dificultades en el proceso de implementación de las NIIF para PyME en el contexto europeo, tomando en consideración el caso de Croacia, señala que los emisores de normas en la UE tratan de disminuir las cargas en cuanto a la presentación de informes de las PyME, manteniendo la información que es relevante para los usuarios de dichos informes y considerando al mismo tiempo objetivos para la armonización contable. Se concluye que la armonización contable es una oportunidad muy importante junto con la globalización, pero que la propuesta de la IABS está lejos de considerar todos los aspectos importantes de ese proceso, como es el caso de los factores antropológicos y culturales.

El estudio exploratorio realizado por Uyar y Gundormus (2013) a partir de encuestas realizadas a 128 contadores, aborda temas asociados con la profesión y con la cualificación de los profesionales contables en el proceso de armonización contable. Señala que la inadecuada o la falta de capacitación de los profesionales por parte de organismos profesionales, son los mayores obstáculos para el proceso de implementación del estándar de las NIIF para PyME en Turquía. La investigación de carácter cualitativo llevada a cabo por Chand, Patel y White (2015) señala que las NIIF para PyME no son apropiadas para todas las PyME, que se debería considerar la simplificación de los criterios de reconocimiento y medición, así como la divulgación y requisitos de presentación, para reflejar mejor las necesidades de los interesados y las consideraciones de costobeneficio. Los resultados del estudio señalan que los preparadores de la información financiera encuentran más problemas al aplicar las NIIF para PyME que los auditores, y expresan que los factores contextuales específicos de cada país deben ser explicados y aceptados al adoptar este estándar.

El trabajo de Dalla y Meirelles (2015) examina si la adopción de las NIIF para PyME ha causado algún efecto sobre el costo de los créditos bancarios, retomando una muestra de 179 empresas brasileras; encontraron que existe una débil relación entre los costos de los créditos financieros y la medición de la calidad de la información contable. La evidencia no demostró ser consistente a lo largo del tiempo y las variables utilizadas en el estudio no fueron significativas.

En el ámbito nacional, el estudio del proceso de convergencia contable de las empresas PyME hacia las NIIF, desde un enfoque cualitativo, ha sido presentado por Salazar-Baquero (2011); Criado, Rangel y Solano (2014); García y Dueñas (2016). Salazar-Baquero (2011) hace un análisis de los efectos no financieros en la presentación de los reportes bajo las NIIF para PyME, y señala las implicaciones que representa el uso de este estándar, mostrando la relación de la contabilidad y la parte fiscal, y los principales cambios que se esperan en el proceso de convergencia.

Criado et al. (2014) realizan un diagnóstico sobre las condiciones empresariales iniciales que poseen las PyME de varios sectores económicos de la ciudad de Cúcuta, para la implementación del nuevo marco regulatorio contable, encontrando que los preparadores de la información financiera poseen conocimiento 
acerca de la normatividad a aplicar, pero les falta claridad acerca de algunos aspectos de los estados financieros. El proceso de convergencia voluntario aún no se ha iniciado.

La investigación de García y Dueñas (2016) señala que implementar las NIIF para PyME permite presentar estados financieros en similares condiciones que competidores internacionales, incrementando la calidad y la comparabilidad de la información financiera. Los autores señalan que el proceso de convergencia incrementa los costos administrativos de las PyME, destacando que la carga administrativa, la actualización y la capacitación profesional deben ser aspectos a considerar con antelación.

Los efectos del proceso de convergencia, desde una perspectiva cuantitativa, han sido presentados por SS (2011; 2012 y 2015); Salazar-Baquero (2013); Robayo (2016) y Lasso, Vargas y Ruano (2018, p. 9).

Los estudios de la SS han retomado en conjunto el análisis de las empresas de los grupos 1 y 2, y sus consideraciones y resultados ya se han abordado en este numeral. El trabajo de Salazar-Baquero (2013) toma en consideración el caso de una empresa PyME, a partir del cual presentan los efectos financieros y no financieros tras el proceso de convergencia contable hacia las NIIF para PyME; señalan que el proceso conlleva distintos efectos financieros, dependiendo de las consideraciones particulares de la empresa, de la elección de las políticas contables y de la precisión de sus estimaciones contables.

Robayo (2016) desarrolla un trabajo descriptivo, de carácter cualitativo, con una muestra de 39 PyME del Valle, en el cual presenta los factores contables que impactan el patrimonio empresarial, destacándose las variaciones en las cuentas de deudores, inventarios y activos fijos; afirma que un alto porcentaje de las empresas analizadas consideran que sus políticas contables deberán ser adecuadas al nuevo marco regulatorio.

Lasso et al. (2018, p. 9) presentan el efecto patrimonial del proceso de convergencia contable para el Estado de Situación Financiera de Apertura (ESFA) para las PyME que reportaron información a la SS. Los resultados señalan que el efecto general del proceso de convergencia fue negativo sobre el patrimonio de estas empresas. Las cuentas contables de inventarios, cuentas comerciales por cobrar e intangibles presentaron variaciones negativas, mientras que la cuenta de la propiedad planta y equipo presentó incrementos.

\section{Metodología de la investigación}

En este apartado se presentan los criterios aplicados en la selección de la muestra, las variables de estudio y la hipótesis de trabajo.

\section{Selección de la muestra}

La muestra se conforma a partir de dos fuentes de información gestionadas por la SS de Colombia. La primera es la base de datos de las empresas colombianas que presentaron información contable bajo la normativa local, al 31 de diciembre del 2015, de los estados financieros del Balance General y el Estado de Resultados. Esta fuente de información incluye 26533 empresas, que no necesariamente serán catalogados como PyME bajo el marco normativo de las NIIF. La segunda fuente de información es la base de datos de las PyME que presentaron los estados financieros del ESFA al $1^{\circ}$ de enero del 2015, el Estado de Situación Financiera (ESF) al final del 2015 y el 2016, y el Estado de Resultados Integral (ERI), bajo la normatividad de las NIIF, al final del 2015 y el 2016. Estas bases de datos incluyen 16028 PyME. Tomando en consideración que la muestra a trabajar debe ser relacionada y pareada con respecto a las dos fuentes, con cierre al 31 de diciembre de 2015, se procedió a excluir las empresas que no estuviesen reportadas en ambas. La composición de la muestra por secciones económicas se muestra en la Tabla 1 . 
TABLA 1

Secciones por actividad económica, CIIU Rev. $4 A C$.

\begin{tabular}{|l|r|}
\hline \multicolumn{1}{|c|}{ Sección económica CIIU Rev. 4 AC } & \\
& Número de empresas \\
\hline A - Agricultura, ganadería, caza, servicultura y pesca & 802 \\
B - Explotación de minas y canteras & 188 \\
C - Industrias manufactureras & 2.226 \\
E - Distribución de agua; evacuación y tratamiento de aguas & 14 \\
residuales & 1.514 \\
F - Construcción & 4.086 \\
G - Comercio por mayor y por menor; reparación de vehículos & 261 \\
H - Transporte y almacenamiento & 285 \\
I - Alojamiento y sevicios de comida & 365 \\
J - Información y comunicaciones & 542 \\
K - Actividades financieras y de seguros & 1.462 \\
L - Actividades inmobiliarias & 1.008 \\
M - Actividades profesionales, cientificas y técnicas & 567 \\
N - Actividades de servicios administrativos y de apoyo & 73 \\
P - Educación & 49 \\
Q - Actividades de atención en salud humana y asistencia social & 52 \\
R - Actividades artisticas, de entretenimiento y recreación & 72 \\
S - Otras actividades de servicio & 13.566 \\
\hline Total & \\
\hline \multicolumn{2}{|c}{ Fuente: elaboración propia. }
\end{tabular}

A las empresas pareadas se les aplicaron criterios de selección tales como los siguientes: no valores nulos en los ingresos, en las dos fuentes; reporte de valores nulos en el denominador de los indicadores financieros; secciones de actividades económicas con número de empresas menor a 10; empresas con efecto del proceso de convergencia contable para el patrimonio y para la ganancia neta superiores o inferiores a 10 veces (se presentan 99 empresas con efectos patrimoniales con ese criterio, mientras que hay 316 con esa condición en la ganancia neta). Este último criterio se aplica toda vez que las empresas que presentan estos efectos producen un sesgo estadístico relevante en ambas colas de la muestra, para las variables estudiadas. La muestra consolidada es de 13566 empresas y su distribución es en términos de las actividades económicas clasificadas acorde al CIIU Rev 4AC, del DANE, Colombia.

Establecer parejas en la muestra se hace a partir de la relación directa de los estados financieros del balance general bajo el marco local con el ESF, y del estado de resultados bajo la norma local y el ERI, todos retomados con corte al 31 de diciembre del 2015, considerando de esta forma el año de transición señalado para las PyME. Este establecimiento de parejas en las dos fuentes de información permite evaluar el efecto de la convergencia en los factores contable-financieros seleccionados, es decir, se usa información que es comparable para cada empresa de la selección.

\section{Factores contable-financieros}

En el desarrollo de la investigación se han considerado seis cuentas del ESF, cinco del ERI y cinco indicadores financieros, a partir de los cuales se quiere establecer el efecto del proceso de convergencia contable hacia las NIIF de las PyME colombianas.

- Factores del ESF: cuentas comerciales por cobrar (CCC), inventarios, PPE, pasivo corriente y no corriente, patrimonio.

- Factores del ERI: costos y gastos de ventas; gastos de administración; ganancia operacional y ganancia neta. 
- Indicadores: razón corriente (activos corrientes / pasivos corrientes) y solvencia (total activos / total pasivos); endeudamiento (total pasivo / patrimonio); retorno sobre los activos ROA (ganancia operacional / total activos) y retorno sobre el patrimonio ROE (ganancia neta / patrimonio).

La Tabla 2 presenta la estadística descriptiva de los factores contable-financieros que han sido seleccionados en el estudio.

TABLA 2

Estadistica descriptiva de los factores bajo el marco contable local y las NIIF

\begin{tabular}{|c|c|c|c|c|c|c|c|c|}
\hline \multirow{2}{*}{ Factor contable-financiero } & \multicolumn{4}{|c|}{ Marco normativo local (millones de \$) } & \multicolumn{4}{|c|}{ NIIF (millones de \$) } \\
\hline & Mínimo & Máximo & Media & Desv. estándar & Mínimo & Máximo & Media & Desv. estándar \\
\hline Cuentas comerciales por cobrar & 0 & 343.008 & $3.475,7$ & $8.462,0$ & 0 & 299.951 & $2.884,2$ & $7.488,4$ \\
\hline Inventarios & 0 & 271.450 & $1.930,7$ & $5.586,7$ & 0 & 276.803 & $1.912,8$ & $6.167,8$ \\
\hline Propiedad, planta y equipo & 0 & 271.879 & $2.183,0$ & $6.335,0$ & 0 & 402.033 & $3.844,1$ & $11.597,7$ \\
\hline Pasivo corriente & 0 & 309.433 & $4.260,3$ & $9.207,3$ & 0 & 330.894 & $4.226,2$ & $9.877,7$ \\
\hline Pasivo no corriente & 0 & 542.219 & $2.121,7$ & $9.644,8$ & 0 & 541.958 & $2.502,3$ & $9.183,5$ \\
\hline Patrimonio & -36.028 & 615.459 & $7.091,9$ & $18.979,5$ & -27.471 & 566.284 & $6.666,0$ & $17.602,8$ \\
\hline Costos de venta & 0 & 1.994 .486 & $8.683,9$ & $27.860,4$ & 0 & 826.783 & $8.577,3$ & $22.031,7$ \\
\hline Gastos de venta & 0 & 159.973 & $1.172,3$ & $4.160,3$ & 0 & 160.221 & $1.110,3$ & $4.004,5$ \\
\hline Gastos administrativos & 0 & 111.546 & $1.346,5$ & $2.988,8$ & 0 & 94.316 & $1.307,5$ & $2.657,7$ \\
\hline Ganancia operacional & -90.946 & 311.038 & 802,0 & $4.288,6$ & -78.341 & 313.931 & 939,9 & $4.653,1$ \\
\hline Ganancia neta & -99.505 & 282.306 & 427,4 & $4.088,2$ & -55.695 & 237.033 & 428,3 & $3.636,6$ \\
\hline Razón corriente & 0 & 161.904 & 23 & $1.406,9$ & 0 & 161.904 & 30,7 & $1.550,5$ \\
\hline Solvencia & 0 & 320.112 & 67 & $3.132,5$ & 0 & 163.816 & 28,9 & $1.440,1$ \\
\hline Endeudamiento & -1.146 & 8.630 & 3 & 77,5 & -4.679 & 1.881 & 2,2 & 56,8 \\
\hline ROA & -3 & 3 & 0 & 0,1 & -4 & 4 & 0,1 & 0,2 \\
\hline ROE & -111 & 83 & 0 & 1,6 & -167 & 442 & 0,1 & 4,5 \\
\hline
\end{tabular}

Fuente: elaboración propia.

\section{Metodología}

El objetivo del presente estudio es realizar un análisis del efecto que ha tenido el proceso de convergencia contable hacia las NIIF, sobre la información presentada en los estados financieros de las PyME colombianas. Para ello, la metodología de trabajo se centra en establecer diferencias significativas en la información contable reportada bajo los dos marcos normativos, a través de la aplicación de pruebas estadísticas a los factores contable-financieros seleccionados, tomando en consideración el procedimiento estadístico propuesto por Callao et al. (2010, p. 11). Con este propósito se postula la siguiente hipótesis:

Hipótesis $\mathbf{H}_{\mathbf{0 1}}$. Hay diferencias no significativas en los valores de los factores contable-financieros presentados bajo la norma local y bajo las NIIF. 
A cada factor seleccionado, en cada una de las dos fuentes de información relacionadas, se le aplicó la hipótesis de normalidad a través de la prueba de normalidad de Chi-cuadrado, estableciéndose que no seguían una distribución normal. A partir de estos resultados, las diferentes muestras relacionadas (pareadas para cada factor) se someten a la prueba no paramétrica de los signos de Wilcoxon.

En cada resultado alcanzado dentro del trabajo, se establece la variación cuantitativa de los factores seleccionados, debido al proceso de convergencia contable. La variación se calcula a partir de las sumas de las clasificaciones positivas y negativas de la prueba de Wilcoxon para cada factor.

Variación = Sumas bajo las NIIF - Sumas bajo la norma local.

Una vez obtenidas las variaciones para los factores contable-financieros, se procede a establecer la significancia de las variaciones encontradas, a partir del z-estadístico de la prueba de Wilcoxon, a niveles de significancia del $1 \%, 5 \%$ y $10 \%$.

\section{Sensibilidad de los resultados}

El proceso de convergencia contable está relacionado con el diseño e implementación de políticas contables que las empresas deben adecuar a su naturaleza jurídica y a su actividad económica. Por ello, en este apartado se examina si los resultados obtenidos pueden guardar relación con el sector y la actividad económica, con el tamaño empresarial, con el tipo de sociedad constituida y con el tiempo de antigüedad de la organización (Tabla 3).

Con este propósito:

- A partir de la clasificación por el CIIU presentada en la tabla 1, se elabora una submuestra para los sectores industrial, compuesto por las actividades económicas A, B, C y F (4730 empresas), y el sector de comercio y servicios, compuesto por las restantes actividades económicas ( 8836 empresas).

- Se toma en consideración submuestras para siete de las actividades económicas mostradas en la tabla 1: A, C, F, como componentes del sector industrial, y las secciones G, K, M y N para el sector de comercio y servicios.

- Para el análisis por tamaño empresarial se establecen cuatro grupos descritos en la Tabla 3, acordes con el valor de los activos totales.

- En el caso del tipo de sociedad se seleccionaron tres: sociedades anónimas (3134 empresas), sociedades por acciones simplificada (7239) y sociedades limitadas (2187), que representan el 92,6 $\%$ de la muestra.

- La antigüedad empresarial se consideró para cuatro períodos de años.

\section{Prueba de correlación}

Los impactos del proceso de convergencia contable al marco de las NIIF tienen dos fuentes de análisis: los efectos patrimoniales y lo efectos sobre las ganancias netas de las empresas. Este apartado pretende visibilizar la existencia de relaciones entre estos dos efectos, para los cual se construyen las matrices de correlación de Pearson para algunos factores contables del ESF: inventarios y PPE, y otros del ERI: costos y gastos de venta, gastos administrativos. Para ello se calculan las diferencias de estos cinco factores, tomando el valor bajo las NIIF y restándole el valor bajo la norma local. 
TABLA 3

Descripción de las submuestras por tamaño y antigüedad

\begin{tabular}{|l|r|}
\hline \multicolumn{1}{|c|}{ Muestra empresarial por tamaño (total activos) } & Número de empresas \\
\hline Tamaño $1(<3.720$ millones de \$) & 3.391 \\
Tamaño 2 $(<6.700$ millones de \$) & 3.361 \\
Tamaño 3 $(<13.600$ millones de \$) & 3.449 \\
Tamaño 4 $>13.600$ millones de \$) & 3.365 \\
\hline Total & 13.566 \\
\hline \multicolumn{1}{|c|}{ Muestra empresarial por años de constitución } & Número de empresas \\
\hline Fecha de constitución periodo 2008-2016 & 3.401 \\
Fecha de constitución periodo 2000-2007 & 3.426 \\
Fecha de constitución periodo 1989-1999 & 3.577 \\
Fecha de constitución anterior al año 1989 & 3.162 \\
\hline Total & 13.566 \\
\hline
\end{tabular}

Fuente: elaboración propia.

\section{Resultados}

El propósito de este apartado es señalar el efecto del proceso de convergencia contable sobre los factores contable-financieros de las PyME de la muestra y la sensibilidad de esos efectos a ciertos parámetros empresariales. A continuación, se da la explicación de los resultados obtenidos.

\section{Diferencias en la información financiera}

Para la comprobación de la hipótesis $\mathrm{H}_{01}$ se trabajó con la prueba no paramétrica de signos de Wilcoxon, sobre un par de muestras (una recopilada bajo la norma local y la otra bajo las NIIF), cuyos resultados se presentan en la Tabla 4.

Para quince de los dieciséis factores analizados se debe rechazar la hipótesis, con un máximo nivel de error del $10 \%$. Tanto los factores del ESF como los del ERI y cuatro de los indicadores financieros presentan diferencias significativas cuando se considera la presentación de la información bajo PCGA o aplicando las NIIF. Entre los indicadores financieros, el retorno del patrimonio (ROE) es el factor que no presenta diferencias significativas bajo la aplicación de PCGA o las NIIF.

TABLA 4

Resultados de la prueb a de signos de Wilcoxon para la hipótesis $H_{01}$

\begin{tabular}{|c|c|c|c|}
\hline \multirow[t]{2}{*}{ Factor contable-financiero } & \multirow{2}{*}{\multicolumn{2}{|c|}{ Z-estadístico }} & \multirow[b]{2}{*}{$\mathrm{Var}$} \\
\hline & & & \\
\hline $\begin{array}{l}\text { Cuentas comerciales por } \\
\text { cobrar }\end{array}$ & $-73,9720$ & *** & - \\
\hline Inventarios & $-8,1310$ & *** & - \\
\hline Propiedad, planta y equipo & 53,8096 & *** & + \\
\hline Pasivo corriente & $-9,0301$ & $* * *$ & - \\
\hline Pasivo no corriente & 33,9808 & *** & + \\
\hline Patrimonio & $-8,9327$ & $* * *$ & - \\
\hline Costos de venta & $-6,7963$ & $* * *$ & - \\
\hline Gastos de venta & $-10,3212$ & *** & - \\
\hline Gastos administrativos & $-4,5231$ & *** & - \\
\hline Ganancia operacional & 13,3681 & $* * *$ & + \\
\hline Ganancia neta & 1,7230 & * & + \\
\hline Razón corriente & $-8,1891$ & $* * *$ & - \\
\hline Solvencia & $-23,5721$ & ${ }^{* * *}$ & - \\
\hline Endeudamiento & 17,5514 & $* * *$ & + \\
\hline ROA & 8,0457 & $* * *$ & + \\
\hline ROE & 0,9478 & & + \\
\hline
\end{tabular}

Fuente: elaboración propia.

*** Rechazar hipótesis nula al $1 \%$ de significancia;

** al $5 \%$ de significancia;

* al $10 \%$ de significancia. 
La prueba no paramétrica de Wilcoxon aporta la suma de las clasificaciones positivas y negativas de las muestras analizadas, a partir de las cuales se puede determinar el signo de la variación que ha experimentado cada uno de los factores objeto de estudio. Tomando en consideración los factores contables-financieros que presentan diferencias significativas, se puede concluir, de manera general, que el proceso de convergencia contable para las PyME colombianas:

- Disminuyó las CCC, los inventarios, los pasivos corrientes, el patrimonio, los costos de ventas, los gastos de ventas y los administrativos.

- Redujo los indicadores de razón corriente y solvencia.

- Incrementó la PPE, el pasivo no corriente, las ganancias operacional y neta, el nivel de endeudamiento y el ROA.

Las cuentas comerciales por cobrar y la cuenta del inventario presentan una disminución de sus valores dentro del proceso de convergencia contable, mientras que se presenta un incremento en el valor del componente de la PPE; el pasivo se incrementa jalonado por el valor superior presentado por el pasivo no corriente; el patrimonio de las empresas objeto de estudio presenta un decrecimiento; la posición financiera muestra un desmejoramiento con referencia a los indicadores de liquidez y de endeudamiento (toda vez que este se incrementó), mientras que el retorno sobre activos ROA y sobre el patrimonio ROE presentan una mejor posición Para este último indicador, la variación positiva generada no es significativa. Por otra parte, los factores asociados al estado financiero ERI presentan decrecimientos en cuanto a los costos y gastos, mientras que las ganancias operacional y neta presentan un incremento. Los resultados de los factores del ESF y del ERI son concordantes con lo señalado por la SS en los trabajos de proyección (SS, 2011; SS, 2012) y con los resultados preliminares de los grupos 1 y 2 (SS, 2015).

\section{Análisis de sensibilidad de las diferencias en la información financiera}

Para cada submuestra señalada en el apartado 3.4 se trabaja con la prueba no paramétrica de los signos de Wilcoxon para cada uno de los factores contable-financieros seleccionados, retomando la hipótesis $\mathrm{H}_{01}$ trabajada en el punto anterior.

\section{Sector de operación}

A partir de la submuestra construida para los dos sectores de operación, los resultados (Tabla 5) muestran que el efecto del proceso de convergencia contable para las PyME con actividades divididas en los sectores industrial y de comercio y servicios no posee una diferenciación relevante.

Todos los factores estudiados presentan una diferencia significativa para ambos sectores, excepto el caso del factor del indicador ROA, cuya variación es significativa para el sector comercio y servicios, pero no lo es para el sector industrial. Para los factores del sector industrial (costo de venta, gastos administrativos, ganancia neta y ROA), el nivel de error estadístico asociado con el nivel de significancia de la prueba de Wilcoxon es menor que el alcanzado en el de comercio y servicios.

A partir de la suma de las clasificaciones positivas y negativas reportadas por la prueba de signos de Wilcoxon, se puede establecer que:

- El sector industrial presenta incrementos en la PPE, el pasivo no corriente, los gastos administrativos y la ganancia operacional; los restantes factores del ESF y el ERI decrecieron. Los indicadores 
de liquidez y rentabilidad presentan una disminución, mientras que el nivel de endeudamiento se incrementó para las PyME de este sector.

- En el sector comercio y servicios se reportan incrementos en los factores de la PPE, los pasivos no corrientes, las ganancias operacional y neta; los restantes factores contables presentan decrecimientos. Los indicadores de liquidez muestran disminución de sus valores en el sector, mientras que el nivel de endeudamiento y los dos indicadores de rentabilidad se incrementan.

TABLA 5

Resultados de la prueba de los signos de Wilcoxon para el sector operación

\begin{tabular}{|c|c|c|c|c|c|}
\hline \multirow[t]{2}{*}{ Factor contable-financiero } & \multicolumn{2}{|c|}{ S. Industrial } & \multicolumn{3}{|c|}{ S. Comercio y Servicios } \\
\hline & Z-estadístico & Var & Z-estadistic & & Var \\
\hline $\begin{array}{l}\text { Cuentas comerciales por } \\
\text { cobrar }\end{array}$ & $-44,1071 * *$ & - & $-59,3271$ & & - \\
\hline Inventarios & $-8,0232 * *$ & - & $-3,4557$ & *** & - \\
\hline Propiedad, planta y equipo & $37,7675 * *$ & + & 38,6779 & $* * *$ & + \\
\hline Pasivo corriente & $-4,5993 * *$ & - & $-7,9576$ & *** & - \\
\hline Pasivo no corriente & $20,7575 * *$ & + & 26,9127 & *** & + \\
\hline Patrimonio & $-5,6816 * *$ & - & $-6,8681$ & *** & - \\
\hline Costos de venta & $-1,7446 *$ & - & $-7,5321$ & *** & - \\
\hline Gastos de venta & $-4,4242 * *$ & - & $-9,5451$ & *** & - \\
\hline Gastos administrativos & $2,2631 * *$ & + & $-6,9979$ & $* * *$ & - \\
\hline Ganancia operacional & $3,8060 * *$ & + & 13,6845 & $* * *$ & + \\
\hline Ganancia neta & $-2,0842 * *$ & - & 3,7362 & *** & + \\
\hline Razón corriente & $-5,0098 * *$ & - & $-6,4805$ & *** & - \\
\hline Solvencia & $-14,4018 * *$ & - & $-18,6760$ & *** & - \\
\hline Endeudamiento & 11,6651 ** & + & 13,2089 & *** & + \\
\hline ROA & $-1,0886$ & - & 10,5000 & *** & + \\
\hline ROE & $-2,1421 * *$ & & 2,7510 & *** & + \\
\hline
\end{tabular}

$$
\begin{aligned}
& \text { Fuente: elaboración propia. } \\
& \text { *** Rechazar hipótesis nula al } 1 \% \text { de significancia; }^{* *} \text { al } 5 \% \text { de significancia; } \\
& { }^{*} \text { al } 10 \% \text { de significancia. }
\end{aligned}
$$

\section{Secciones de actividad económica}

En este apartado se analiza con mayor detalle la dinámica del proceso de convergencia contable de las PyME hacia el marco normativo de las NIIF, a nivel de actividades económicas, tomando para ello algunas secciones económicas. Los resultados de la prueba de los signos de Wilcoxon para los factores contable-financiero de siete secciones muestran que existen diferencias relevantes en el impacto que cada una ellas experimentó en este proceso (Tabla 6).

Las secciones $\mathrm{K}$, actividades financieras, A y actividades agrícolas, son las menos afectadas por la aplicación de las NIIF para PyME. Cada una de ellas posee cinco factores contable-financiero, del ESF y ERI, que no presentan variaciones significativas al cambiar el marco normativo contable, mientras que dentro de los indicadores financieros solo el ROE no presenta diferencias significativas.

La sección G, comercio por mayor y por menor, es la más afectada por la convergencia contable, toda vez que solo dos de los factores bajo estudio no poseen cambios significativos; la sección C, industrias manufactureras, es la otra más afectada, presentando tres factores que no poseen cambios significativos al implementar el marco normativo de las NIIF. 
TABLA 6

Resultados de la prueba de los signos de Wilcoxon por actividades económicas

\begin{tabular}{|c|c|c|c|c|c|c|c|c|c|c|c|c|c|c|c|c|c|c|c|}
\hline \multirow[t]{2}{*}{ Factor contable-financiero } & \multicolumn{2}{|l|}{ Sección A } & \multicolumn{3}{|c|}{ Sección C } & \multicolumn{2}{|l|}{ Sección F } & \multicolumn{3}{|c|}{ Sección G } & \multicolumn{3}{|l|}{$\begin{array}{c}\text { Sección } \\
\mathbf{K}\end{array}$} & \multicolumn{3}{|l|}{$\begin{array}{c}\text { Sección } \\
\text { M }\end{array}$} & \multicolumn{3}{|l|}{$\begin{array}{c}\text { Sección } \\
\mathbf{N}\end{array}$} \\
\hline & Z-estadístico & Var. & Z-estadistic & & Var. & Z-estadístico & Var. & Z-estadisti & tico & Var. & Z-estadísti & tico & Var. & Z-estadist & tico & Var. & Z-estadisti & ico & Var \\
\hline Cuentas comerciales por cobrar & $-17,2044^{* * *}$ & - & $-33,2836 *$ & *** & - & $-21,9611^{* * *}$ & - & $-44,6551$ & $* * *$ & - & $-10,0632$ & $* * *$ & - & $-19,1082$ & $* * *$ & - & $-14,6290$ & $* * *$ & - \\
\hline Inventarios & $-17,2867 \quad * * *$ & - & $-1,5765$ & & - & $3,0451 \quad * * *$ & + & $-2,1594$ & $* *$ & - & $-0,9885$ & & - & $-0,1237$ & & - & $-0,9456$ & & - \\
\hline Propiedad, planta y equipo & $13,3599^{* * *}$ & + & $32,7928 *$ & $* * *$ & + & $14,1113 * * *$ & + & 34,9605 & $* * *$ & + & 4,5358 & $* * *$ & + & 11,5717 & $* * *$ & + & 10,6198 & $* * *$ & + \\
\hline Pasivo corriente & $-0,4628$ & - & $-3,8142 *$ & *** & - & $-2,5210^{* *}$ & - & $-5,0952$ & $* * *$ & - & $-1,8136$ & $*$ & - & $-4,9737$ & $* * *$ & - & $-1,2877$ & & - \\
\hline Pasivo no corriente & $9,4929 * * *$ & + & $16,8971 *$ & $* * *$ & + & $7,9960^{* * *}$ & + & 17,0602 & $* * *$ & + & 7,1651 & $* * *$ & + & 8,9253 & $* * *$ & + & 5,4969 & $* * *$ & + \\
\hline Patrimonio & $-2,8251 \quad * * *$ & - & $-1,9598 *$ & * & - & $-5,8733^{* * *}$ & - & $-1,8724$ & * & - & $-8,4000$ & $* * *$ & - & $-4,4418$ & *** & - & $-1,9765$ & ** & - \\
\hline Costos de venta & 0,0050 & + & $-3,9677 *$ & $* * *$ & - & $1,7438 *$ & + & $-13,0444$ & $* * *$ & - & 2,9022 & $* * *$ & + & 1,6192 & & + & 2,3718 & $* *$ & + \\
\hline Gastos de venta & $-1,5735$ & - & $-2,7306 *$ & $* * *$ & - & $-2,9182 * * *$ & - & $-6,9026$ & $* * *$ & - & $-1,8839$ & $*$ & - & $-2,8610$ & $* * *$ & - & $-1,9223$ & $*$ & - \\
\hline Gastos administrativos & 0,1921 & + & $2,1692 *$ & ** & + & 1,1241 & + & $-0,3804$ & & - & 0,2635 & & + & $-3,4834$ & $* * *$ & - & $-2,6290$ & $* * *$ & - \\
\hline Ganancia operacional & $7,6834^{* * *}$ & + & $-1,0467$ & & - & $2,2655 * *$ & + & 9,5184 & $* * *$ & + & $-0,4355$ & & - & 3,1903 & $* * *$ & + & 0,0705 & & + \\
\hline Ganancia neta & $-0,9711$ & - & 0,4465 & & + & $-3,0711^{* * *}$ & - & $-0,1343$ & & - & $-1,4996$ & & - & 2,0386 & ** & + & 1,3806 & & + \\
\hline Razón corriente & $-2,6527 * * *$ & - & $-5,4149 *$ & $* * *$ & - & $-0,7957$ & - & $-6,0426$ & $* * *$ & - & $-0,0580$ & & - & 0,4610 & & + & $-3,7511$ & $* * *$ & - \\
\hline Solvencia & $-9,2000^{* * *}$ & - & $-8,7368 *$ & $* * *$ & - & $-7,3412 * * *$ & - & $-6,6243$ & $* * *$ & - & $-10,6115$ & $* * *$ & - & $-6,5281$ & $* * *$ & - & $-5,3188$ & $* * *$ & - \\
\hline Endeudamiento & $6,5552^{* * *}$ & + & $7,6735 *$ & *** & + & $6,2652^{* * *}$ & + & 5,9945 & $* * *$ & + & 9,1162 & $* * *$ & + & 4,6091 & $* * *$ & + & 2,8531 & $* * *$ & + \\
\hline ROA & $6,0797 * * *$ & + & $-5,0087 *$ & *** & - & 0,3509 & + & 6,3848 & $* * *$ & + & 2,4252 * & $* *$ & + & 2,5876 & $* * *$ & + & $-0,7921$ & & - \\
\hline ROE & $-0,7008$ & - & $-1,8762 *$ & * & - & $-0,5113$ & - & $-2,1076$ & $* *$ & - & 1,3976 & & + & 3,6797 & $* * *$ & + & 1,1111 & & + \\
\hline
\end{tabular}

Fuente: elaboración propia.

*** Rechazar hipótesis nula al $1 \%$ de significancia;

** al $5 \%$ de significancia;

$*$ al $10 \%$ de significancia.

Los factores contables de las CCC, la PPE, el pasivo no corriente y el patrimonio presentan variaciones significativas en las siete secciones estudiadas; estos son resultados que concuerdan con lo presentado por la Superintendencia de Sociedades de Colombia para las empresas de los grupos 1 y 2 (SS, 2011; SS, 2012; SS, 2015). Los indicadores de solvencia y endeudamiento poseen diferencias significativas en todas las secciones.

Los factores contables referentes a los inventarios, el pasivo corriente, el costo de venta, los gastos de venta y administrativos, y las ganancias operacional y neta presentan comportamientos diferentes respecto de la significancia estadística, dependiendo de la actividad económica. Esto puede ser atribuido a la conceptualización y al alcance de las políticas contables que fueron diseñadas e implementadas por cada empresa, toda vez que estas retoman la naturaleza del negocio, así como la estructura financiera por la que optaron ellas al estar en una determinada actividad económica.

A partir de la suma de las clasificaciones positivas y negativas de las muestras que aporta la prueba Wilcoxon, se determinó el signo de la variación para cada factor objeto de estudio. En resumen, se puede indicar que el resultado del proceso de convergencia contable para las PyME de las secciones revisadas presenta:

- Un decrecimiento de las CCC, del pasivo corriente, del patrimonio y de los gastos en las ventas, así como el indicador de solvencia en todas las secciones. El indicador del ROE se desmejora para cuatro, exceptuando las secciones $\mathrm{K}, \mathrm{M}$ y $\mathrm{N}$.

- Un incremento en la PPE, en el pasivo no corriente y en el nivel de endeudamiento para todas las secciones. Se presenta un aumento en el costo de venta en cinco de las siete secciones. El indicador de rentabilidad ROA se mejora en cinco secciones, exceptuando las secciones $\mathrm{C}$ y $\mathrm{N}$. 
En términos generales, estos resultados son consistentes con los encontrados en la muestra general presentada al inicio de este apartado de resultados.

\section{Tamaño empresarial}

A partir de los datos revelados en la Tabla 7 se observa que no existe una variación relevante por el efecto de la implementación de las NIIF en las PyME colombianas, cuando se toman en consideración el tamaño de las mismas. La afectación por el proceso de convergencia contable, en general, mantiene su significancia en los factores estudiados, excepto el caso de la ganancia neta, en la cual la variación no presenta una diferencia significativa.

Existe un comportamiento diverso en el indicador de rentabilidad ROE, ya que para los grupos de menor y mayor tamaño es significativa la diferencia de la información contable presentada bajo la norma local y bajo las NIIF; para los otros dos no es significativa.

Las variaciones de los factores contables bajo estudio presentan un comportamiento similar en los cuatro tamaños empresariales, obteniéndose a partir de las sumas de las clasificaciones de la prueba de Wilcoxon, por lo que se presenta:

- Un decrecimiento de las CCC, del inventario, del pasivo corriente, del patrimonio, de los costos de ventas y gastos de ventas, así como en los gastos administrativos. Ambos indicadores de liquidez se deterioran.

- Un incremento en la PPE, el pasivo no corriente y en la ganancia operacional y la neta. Se aumenta el nivel de endeudamiento y se mejoran los indicadores de rentabilidad, excepto el ROE para uno de los grupos.

TABLA 7

Resultados de la prueba de los signos de Wilcoxon por tamaño empresarial

\begin{tabular}{|c|c|c|c|c|c|c|c|c|c|c|c|c|}
\hline \multirow[t]{2}{*}{ Factor contable-financiero } & \multicolumn{3}{|c|}{ Tamaño1 } & \multicolumn{3}{|c|}{ Tamaño2 } & \multicolumn{3}{|c|}{ Tamaño3 } & \multicolumn{3}{|c|}{ Tamaño4 } \\
\hline & \multicolumn{2}{|c|}{ Z-estadístico } & \multirow{2}{*}{\begin{tabular}{|c|} 
Var \\
- \\
\end{tabular}} & \multicolumn{2}{|c|}{ Z-estadístico } & \multirow{2}{*}{\begin{tabular}{|c|} 
Var \\
- \\
\end{tabular}} & \multicolumn{2}{|c|}{ Z-estadístico } & \multirow{2}{*}{\begin{tabular}{|c|} 
Var \\
- \\
\end{tabular}} & \multicolumn{2}{|c|}{ Z-estadístico } & \multirow{2}{*}{$\begin{array}{c}\text { Var } \\
-\end{array}$} \\
\hline Cuentas comerciales por cobrar & $-39,5178$ & $* * *$ & & $-37,1931$ & $* * *$ & & $-36,9097$ & $* * *$ & & $-35,5780$ & $* * *$ & \\
\hline Inventarios & $-4,4666$ & $* * *$ & - & $-6,7424$ & $* * *$ & - & $-4,4894$ & $* * *$ & - & $-1,7316$ & $*$ & - \\
\hline Propiedad, planta y equipo & 23,3215 & $* * *$ & + & 24,5849 & $* * *$ & + & 27,6453 & $* * *$ & + & 31,7152 & $* * *$ & + \\
\hline Pasivo corriente & $-6,9829$ & $* * *$ & - & $-5,6735$ & $* * *$ & - & $-5,3300$ & $* * *$ & - & $-1,4486$ & & - \\
\hline Pasivo no corriente & 11,7166 & $* * *$ & + & 13,7578 & $* * *$ & + & 17,4190 & $* * *$ & + & 20,5886 & $* * *$ & + \\
\hline Patrimonio & $-8,8183$ & $* * *$ & - & $-5,4795$ & $* * *$ & - & $-0,4884$ & & - & $-2,4507$ & $* *$ & - \\
\hline Costos de venta & $-4,6343$ & $* * *$ & - & $-1,9944$ & $* *$ & - & $-4,0171$ & $* * *$ & - & $-3,2513$ & $* * *$ & - \\
\hline Gastos de venta & $-5,1304$ & $* * *$ & - & $-3,8173$ & $* * *$ & - & $-6,2717$ & $* * *$ & - & $-5,2520$ & $* * *$ & - \\
\hline Gastos administrativos & $-0,4209$ & & - & $-2,5271$ & $* *$ & - & $-2,2409$ & $* *$ & - & $-3,4148$ & $* * *$ & - \\
\hline Ganancia operacional & 1,9517 & $*$ & + & 5,1284 & $* * *$ & + & 8,2904 & $* * *$ & + & 9,2417 & $* * *$ & + \\
\hline Ganancia neta & 1,2449 & & + & 1,0736 & & + & 0,9565 & & + & 0,7328 & & + \\
\hline Razón corriente & $-4,7434$ & $* * *$ & - & $-2,7444$ & $* * *$ & - & $-2,5958$ & $* * *$ & - & $-6,2870$ & $* * *$ & - \\
\hline Solvencia & $-11,0699$ & $* * *$ & - & $-11,9369$ & $* * *$ & - & $-9,5497$ & $* * *$ & - & $-14,3956$ & $* * *$ & - \\
\hline Endeudamiento & 8,3536 & $* * *$ & + & 8,8862 & $* * *$ & + & 7,0549 & $* * *$ & + & 10,5543 & $* * *$ & + \\
\hline ROA & 2,4990 & $* *$ & + & 3,9540 & $* * *$ & + & 5,7556 & $* * *$ & + & 4,2243 & $* * *$ & + \\
\hline ROE & 3,2899 & $* * *$ & + & 0,2350 & & + & 0,0916 & & + & $-1,6997$ & $*$ & - \\
\hline
\end{tabular}

Fuente: elaboración propia.

*** Rechazar hipótesis nula al $1 \%$ de significancia;

** al $5 \%$ de significancia;

* al $10 \%$ de significancia. 


\section{Tipo de sociedad empresarial}

El análisis de sensibilidad del proceso de convergencia contable a las NIIF presenta un comportamiento con diferencias relevantes cuando se explora la condición del tipo de sociedad de las empresas. Aunque las PyME de la muestra poseen ocho tipos de sociedades, aquí solo se examinan las sociedades anónimas, las sociedades anónimas simplificadas y las sociedades limitadas, que representan el 92,6\% de la muestra.

Los resultados de la prueba de Wilcoxon (Tabla 8) muestran que las empresas establecidas como sociedad por acciones simplificada (SAS), que representan el 53,4\% de la muestra, han tenido el mayor efecto en el proceso de convergencia, presentando diferencias significativas en todos factores contable-financieros analizados. La PPE, el pasivo no corriente, las ganancias operacional y neta, el nivel de endeudamiento y los indicadores de rentabilidad presentan incrementos en estas empresas; los demás factores manifiestan un efecto negativo en sus valores.

TABLA 8

Resultados de la prueba de los signos de Wilcoxon por tipo sociedad

\begin{tabular}{|c|c|c|c|c|c|c|c|c|c|}
\hline \multirow[t]{2}{*}{ Factor contable-financiero } & \multicolumn{3}{|l|}{ Soc. SAS } & \multicolumn{3}{|l|}{$\begin{array}{c}\text { Soc. } \\
\text { anónimas }\end{array}$} & \multicolumn{3}{|l|}{ Soc. Ltda. } \\
\hline & $\begin{array}{c}\text { Z- } \\
\text { estadístico } \\
\end{array}$ & & Var & $\begin{array}{c}\text { Z- } \\
\text { estadístico }\end{array}$ & & Var & $\begin{array}{c}\text { Z- } \\
\text { estadístico } \\
\end{array}$ & & Var \\
\hline Cuentas comerciales por cobrar & $-53,7875$ & *** & - & $-36,0414$ & *** & - & $-30,9889$ & $* * *$ & - \\
\hline Inventarios & $-4,6189$ & $* * *$ & - & $-5,8617$ & $* * *$ & - & $-2,2912$ & ** & - \\
\hline Propiedad, planta y equipo & 34,9277 & $* * *$ & + & 32,2784 & *** & + & 24,5586 & $* * *$ & + \\
\hline Pasivo corriente & $-6,5334$ & $* * *$ & - & $-2,9977$ & *** & - & $-4,6297$ & *** & - \\
\hline Pasivo no corriente & 22,6697 & $* * *$ & + & 20,1831 & *** & + & 12,8404 & ${ }^{* * *}$ & + \\
\hline Patrimonio & $-6,3155$ & $* * *$ & - & $-7,4817$ & $* * *$ & - & 0,5352 & & + \\
\hline Costos de venta & $-5,2086$ & $* * *$ & - & $-5,0665$ & $* * *$ & - & $-2,5211$ & $* *$ & - \\
\hline Gastos de venta & $-7,9928$ & $* * *$ & - & $-4,5592$ & *** & - & $-3,6766$ & *** & - \\
\hline Gastos administrativos & $-3,5569$ & $* * *$ & - & $-2,5496$ & ** & - & $-1,2197$ & & - \\
\hline Ganancia operacional & 9,0440 & $* * *$ & + & 7,0045 & $* * *$ & + & 4,5840 & $* * *$ & + \\
\hline Ganancia neta & 1,9852 & ** & + & 0,9800 & & + & $-0,2421$ & & - \\
\hline Razón corriente & $-5,7869$ & $* * *$ & - & $-6,3010$ & *** & - & $-2,0800$ & $* *$ & - \\
\hline Solvencia & $-15,8240$ & *** & - & $-16,2277$ & *** & - & $-4,6947$ & *** & - \\
\hline Endeudamiento & 11,2277 & $* * *$ & + & 13,4716 & *** & + & 4,2033 & $* * *$ & + \\
\hline ROA & 5,8069 & $* * *$ & + & 4,0771 & *** & + & 0,7232 & & + \\
\hline ROE & 2,0716 & ** & + & 0,4293 & & + & $-2,5172$ & $* *$ & - \\
\hline
\end{tabular}

$$
\begin{aligned}
& \text { Fuente: elaboración propia. } \\
& \text { *** Rechazar hipótesis nula al } 1 \% \text { de significancia; } \\
& { }^{* *} \text { al } 5 \% \text { de significancia; } \\
& { }^{*} \text { al } 10 \% \text { de significancia. }
\end{aligned}
$$

Las PyME constituidas como sociedades limitadas, que representan el 16,1\% de la muestra, son las que menor efecto registran dentro del proceso de convergencia contable hacia las NIIF. Para estas empresas se presentaron crecimientos en la PPE, el pasivo corriente, el patrimonio y la ganancia operacional. De igual forma, los indicadores de endeudamiento y rentabilidad sobre los activos ROA exhiben incrementos. En los restantes factores del estudio se presentan decrecimientos en sus valores al estar bajo el enfoque de las NIIF. En este subgrupo, las diferencias que se demuestran en tres factores contables son no significativas como consecuencia del cambio normativo, situación que se da también en el indicador de rentabilidad ROA.

En las empresas constituidas como sociedades anónimas, los resultados de la prueba de Wilcoxon señalan que dos factores indican variaciones que no anuncian diferencias significativas en el proceso de convergencia: ganancia neta e indicador ROE. En los factores de PPE, pasivo no corriente, patrimonio, ganancias operacional y neta, así como en los indicadores de endeudamiento y rentabilidad ROA y ROE se señala una variación positiva en sus valores bajo el nuevo enfoque de las NIIF.

En resumen, los factores de patrimonio y ganancias netas, y el indicador de rentabilidad ROE presentan un comportamiento diverso en cuanto a las diferencias significativas surgidas de la implementación de las NIIF, cuando se toma en consideración el origen constitutivo de ellas. 


\section{Por antigüedad en la constitución empresarial}

Los resultados de la prueba de signos de Wilcoxon, en la submuestra que retoma el tiempo de constitución de las PyME, indican que el efecto del proceso de convergencia hacia las NIIF no presenta una diferencia relevante en los cuatro rangos de tiempo examinados (Tabla 9).

TABLA 9

Resultados de la prueba de los signos de Wilcoxon por años de constitución

\begin{tabular}{|c|c|c|c|c|c|c|c|c|c|}
\hline \multirow[t]{2}{*}{ Factor contable-financiero } & \multicolumn{2}{|l|}{ 2016-2008 } & \multicolumn{3}{|c|}{$2007-2000$} & \multicolumn{2}{|l|}{ 1999-1989 } & \multicolumn{2}{|l|}{ Menor a 1989} \\
\hline & Z-estadístico & Var & Z-estadístic & & Var & Z-estadístico & Var & Z-estadístico & Var \\
\hline Cuentas comerciales por cobrar & $-34,0346 * * *$ & - & $-38,4882 *$ & $* * *$ & - & $-39,2182 * * *$ & - & $-36,1741^{* * *}$ & - \\
\hline Inventarios & $-1,2514$ & - & $-3,5984 *$ & $* * *$ & - & $-3,5541^{* * *}$ & - & $-7,7027^{* * *}$ & - \\
\hline Propiedad, planta y equipo & $15,5040^{* * *}$ & + & $26,2363 *$ & $* * *$ & + & $30,8756^{* * *}$ & + & $33,1832^{* * *}$ & + \\
\hline Pasivo corriente & $-6,0999 * * *$ & - & $-4,2746 *$ & $* * *$ & - & $-3,1444^{* * *}$ & - & $-4,4228 * * *$ & - \\
\hline Pasivo no corriente & $13,1422^{* * *}$ & + & $14,2245 *$ & $* * *$ & + & $18,1581^{* * *}$ & + & $22,6958^{* * *}$ & + \\
\hline Patrimonio & $-4,1391 * * *$ & - & $-1,9301 *$ & $*$ & - & $-2,2250^{* *}$ & - & $-9,2578^{* * *}$ & - \\
\hline Costos de venta & $-1,8942 *$ & - & $-4,5022 *$ & $* * *$ & - & $-3,1777^{* * *}$ & - & $-4,0314^{* * *}$ & - \\
\hline Gastos de venta & $-3,8344^{* * *}$ & - & $-6,0928 *$ & *** & - & $-5,0002^{* * *}$ & - & $-5,6605^{* * *}$ & - \\
\hline Gastos administrativos & $-3,1168 * * *$ & - & $-3,7705 *$ & *** & - & $-2,6860^{* * *}$ & - & 0,5767 & + \\
\hline Ganancia operacional & $4,7996^{* * *}$ & + & $5,4390 *$ & $* * *$ & + & $6,5648^{* * *}$ & + & $10,0223 * * *$ & + \\
\hline Ganancia neta & $2,3971 * *$ & + & $1,8373 *$ & $*$ & + & $-0,0657$ & - & $-0,7302$ & - \\
\hline Razón corriente & $-2,2271^{* *}$ & - & $-5,4362 *$ & $* * *$ & - & $-4,6800^{* * *}$ & - & $-4,0001 \quad * * *$ & - \\
\hline Solvencia & $-8,4978^{* * *}$ & - & $-8,5223 *$ & $* * *$ & - & $-10,9794^{* * *}$ & - & $-18,2587^{* * *}$ & - \\
\hline Endeudamiento & $4,4722 * * *$ & + & $6,2175 *$ & $* * *$ & + & $9,6904 * * *$ & + & $15,5949^{* * *}$ & + \\
\hline ROA & $3,1228^{* * *}$ & + & $2,0054 *$ & $* *$ & + & $2,9109^{* * *}$ & + & $8,3669^{* * *}$ & + \\
\hline ROE & 1,3595 & + & $-0,5359$ & & - & $-0,6704$ & - & $1,7601 *$ & + \\
\hline
\end{tabular}

Los factores contables de inventarios, gastos administrativos y ganancia neta, y el indicador ROE presentan un comportamiento diverso en los grupos de análisis. Tres grupos poseen dos factores que no ofrecen diferencias significativas al converger hacia el marco normativo de las NIIF.

$\mathrm{Al}$ retomar las clasificaciones positivas y negativas reportadas por la prueba de signos de Wilcoxon, se puede establecer lo siguiente:

- Los factores que presentan decrecimientos en los cuatro grupos de empresas son: CCC, inventarios, pasivo corriente, patrimonio, costos y gastos de ventas; de igual forma, los dos indicadores de liquidez anuncian una disminución en todos ellos.

- La PPE, el pasivo no corriente y la ganancia Operacional se incrementaron como producto del proceso de convergencia contable; los indicadores de endeudamiento y rentabilidad sobre el activo ROA se incrementaron.

\section{Correlación de resultados}

Otros asuntos de interés en este trabajo están relacionados con los incrementos en la PPE y la disminución del inventario que se presenta en el proceso de convergencia. El primer asunto fue señalado por la SS en los trabajos previos de pronóstico de impactos del proceso (SS, 2011; SS, 2012); en ellos se señaló que esto se daría al retomar la revalorización de activos, lo que podría llevar a una disminución de los gastos administrativos en el ERI, toda vez que si se mantuviesen los períodos de vida útil de la PPE, esto llevaría a una disminución de la alícuota de la depreciación contable. Sin embargo, este impacto se puede balancear al incrementar los períodos de vida útil de la PPE. El segundo asunto tiene relación con el reconocimiento y medición de los costos y gastos de ventas en el ERI (CTCP, 2015), por lo cual el decrecimiento del inventario debería estar relacionado con costos y gastos de venta reportados. Por otro lado, el trabajo de Bohórquez (2015) señala que la valuación, el costo y la presentación de los inventarios cambian al utilizarse las NIIF, indicando que el 
no poder utilizar el método UEPS (últimos en entrar, primeros en salir) para su medición conlleva no poder registrar mayores valores en el costo y tener que representar el valor de los inventarios a partir del valor de mercado de ellos.

En este apartado del trabajo se parte del cálculo de las diferencias de estas cinco variables, tomando el valor bajo las NIIF y restando el valor bajo la norma local, es decir, el efecto cuantitativo directo. Para estas diferencias se construyen dos matrices de correlaciones lineales de Pearson: una para la PPE y otra para los inventarios. Las matrices de correlación de Pearson determinan el grado de relación entre dos series de datos, cuyos valores van entre $-1 \mathrm{y}+1$.

La Tabla 10 presenta los resultados de las matrices de Pearson, a partir de los cuales se denota una relación positiva baja entre el efecto en los inventarios y los costos y gastos de venta, indicando que si el primero disminuye, los segundos también lo harán en la proporción señalada por los coeficientes de la matriz. Se denota así una mayor relación del efecto en los inventarios con los gastos de ventas, que obedece al ajuste que tiene el valor de los inventarios al valor de mercado; este ajuste se refleja en los valores registrados en los gastos del Estado de Resultados Integral (SS, 2102; CTCP, 2015; Bohórquez, 2015).

TABLA 10

Matrices de correlación Pearson para los factores contables inventarios y PPE

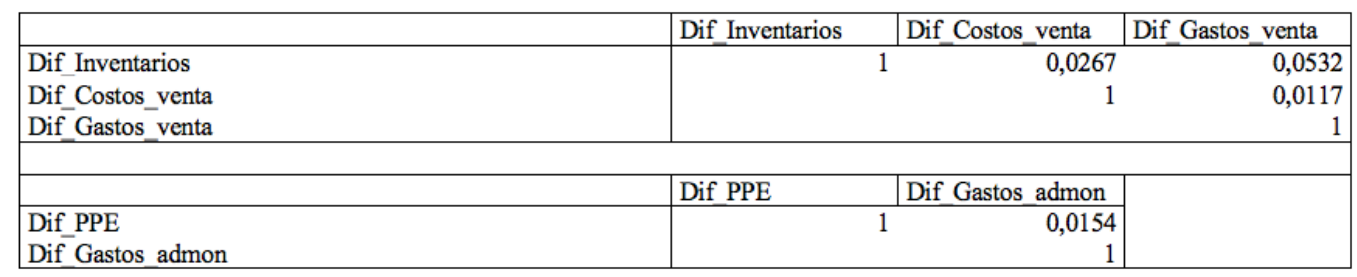

Fuente: elaboración propia.

La correlación del efecto de la PPE con los gastos administrativos es positiva, es decir, el incremento de la PPE conlleva aumentos en los gastos administrativos, lo que se puede explicar de que a mayores valores reconocidos de la PPE, mayor será el valor de alícuota de su depreciación en la proporción señalada por el coeficiente de la matriz.

\section{Conclusiones}

En el proceso de convergencia contable de las PyME colombianas se destacan las variaciones negativas de los factores contables, como las cuentas comerciales por cobrar, los inventarios, el pasivo corriente, el patrimonio y los indicadores de liquidez: razón corriente y solvencia, mientras que se presentan variaciones positivas en los factores de propiedad, planta y equipo, en los pasivos no corrientes, el nivel de endeudamiento, el ROA y el ROE. Es decir, se presentan efectos de variaciones positivas y negativas con significancia estadística en los factores analizados, excepto el ROE.

En cuanto al estado de resultados se presentaron efectos negativos en costos de venta y en gastos de venta y administrativos, mientras que las ganancias operacional y neta poseen efectos positivos. Estos efectos, desde el punto de vista cuantitativo, fueron expuestos en los trabajos de pronóstico y presentación de resultados de la SS (2011, 2012 y 2015).

Los efectos generados por la convergencia contable hacia las NIIF son sensibles a la naturaleza de las actividades económicas que desarrollan las empresas. Estos efectos poseen significancia estadística, pero los signos de las variaciones causadas dependen, en algunos factores, de la naturaleza de las actividades económicas, tomadas grupalmente o por secciones económicas. La sección de las actividades financieras es la que menos efecto con significancia percibió, mientras que las secciones de comercio por mayor y por menor, y la de industrias manufactureras presentan la mayor variación significativa en el proceso. Esta sensibilidad de los impactos de la convergencia por actividad empresarial está señalada en el trabajo de pronóstico de la SS 
(2011; 2012) y Lasso et al. (2018, p. 18). No se nota sensibilidad en la significancia de las variaciones cuando se retoman el tamaño de las empresas, determinado a partir de los activos, y los años de constitución de las empresas de la muestra. Cuando se revisa el efecto de la convergencia contable hacia las NIIF, tomando en consideración el tipo de sociedad de la empresa, las variaciones en los grupos analizados presentan diferencias significativas; las empresas constituidas como sociedades limitadas son las menos afectadas.

En algunos factores contables patrimoniales, inventarios y propiedad, planta y equipo (PPE), se presenten efectos correlacionales positivamente con otros del estado de resultados: costos y gastos de ventas, y gastos administrativos. Los valores de los coeficientes de correlación presentados en la tabla 10 señalan que ella es baja. Este aspecto también fue señalado por la SS (2012), CTCP (2015), Bohórquez (2015) y SalazarBaquero, y puede explicarse, por una parte, a partir del hecho de que un incremento en la PPE puede generar una menor o mayor alícuota de la depreciación, dependiendo de las políticas contables asumidas para la vida útil de ella. Por otra parte, la variación en los inventarios obedece al ajuste del valor de ellos al de mercado; ajuste que se refleja en las variaciones que tendrán los gastos del Estado de Resultados Integral.

\section{Referencias bibliográficas}

Alvarado, M., Ampudia, J. M. y Prado, M. (2009). Análisis del impacto de las normas internacionales de contabilidad sobre el patrimonio neto y resultados de los grupos no financieros del IBEX-35. Investigaciones europeas de dirección y economía de la empresa, 15 (3), 144-162.

Asociación Nacional de Instituciones Financieras (ANIF). (2017). Gran encuesta PyME. Informe de resultados del primer semestre de 2017. Recuperado el 24 de abril de 2018 de: https://anif.co/sites/default/files/encuestas_p yme/2017/12/gepnacional_i-17.pdf

Baldarelli, M. G, Demartini, P., Mosnja-Skare, L. y Paoloni, P. (2012). Accounting Harmonization for SME-S in Europe: Some Remarks on IFRS for SMES and Empirical Evidences. Economic Research-Ekonomska Istraživanja, 25, 1-26.

Black, R. e Hiroshi, S. (2016). Heterogeneity in Earnings Quality Between Different Classes of Companies After IFRS Adoption: Evidence from Brazil. Contabilidade \& Finanças, 28, (73), 113-131.

Bohórquez, N. del P. (2015). Implementación de norma internacional de inventarios en Colombia. Innovar, 25 (57), 79-92.

Bohusova, H. (2011). The implementation of the IFRS for SME in the EU. Acta univ. agric. et silvic. Mendel. Brun., 2, 43-50.

Callao, S., Ferrer, C., Jarne, J. I. y Laínez, J. A. (2010). IFRS Adoption in Spain and the United Kingdom: Effects on Accounting Number and Relevance. Incorporating advances in international accounting, 26, 304-313.

Carneiro, J., Rodrigues, L. L. y Craig, R. (2017). Assessing International Accounting Harmonization in Latin America. Accounting Forum, 41 (3), 172-184.

Católico, D. F., Cely, V. R. y Pulido, J. R. (2013). Revelación de la información financiera sobre propiedad, planta y equipo en empresas industriales cotizadas en Colombia. Cuadernos de contabilidad, 14 (36), 943-970.

Chand, P., Patel, A. y White, M. (2015). Adopting International Financial Reporting Standards for Small and Mediumsized Enterprises. Australian Accounting Review, 73, 139-154.

Confetti, R., Da Silva, J., Ambrozinni, M. A., Assaf, A. y Guasti, F. (2016). Impact of Adopting IFRS Standars on the Equity Cost of Brazilian Open Capital Companies. RAM. Revista Administração Mackenzie, 17 (4), 85-108.

Consejo Técnico de la Contaduría Pública (CTCP). (2012). Direccionamiento estratégico del proceso de convergencia de las normas de contabilidad e información financiera y de aseguramiento de la información, con estándares internacionales. Recuperado el 15 de agosto de 2016, de: http://www.ctcp.gov.co/ctcp_documentosDef.php

Consejo Técnico de la Contaduría Pública (CTCP). (2015). Marco conceptual. Orientaciones técnicas sobre la aplicación de la NIIF para las PyME. Recuperado el 26 de septiembre de 2017, de: http://www.ctcp.gov.co/ct cp_documentosDef.php 
Costa dos Santos, M. A. y Nóbrega, P. R. (2014). Effect of Adoption of IFRS on the Information Relevance of Accounting Profits in Brazil. Contabilidade \& Finanças, 25 (66), 228-241.

Criado, Y. K., Rangel, A. C. y Solano, E. (2014). Estudio de las pequeñas empresas de Cúcuta sobre la convergencia a las normas internacionales de información financiera para PyME. Respuestas, 19 (2), 6-14.

Dalla R, E. y Meirelles, S. E. (2015). Adoption of the International Accounting Standard by Small and Medium-Sized Entities and its Effects on Credit Granting. Cont. Fin. USP, São Paulo, 69, 304-316.

Elbakry, A., Nwachukwu J. C., Abdou H. y Elshandidy T. (2017). Taxation Comparative Evidence on the Value Relevance of IFRS-Based Accounting Information in Germany.

European Commission. (2010). Summary Report of the Responses Received to the Commission's Consultation on the Internal Financial Reporting Standard for Small and Mediun-sized Entities. Recuperado el 3 de mayo de 2018 de: http://ec.europa.eu/internal_market/accounting/docs/ifrs/2010-05-31_ifrs_sme_consultation_summary en.pdf

García, C. S. y Dueñas, C. R. (2016). Los aspectos cualitativos en las Pyme y los nuevos retos gerenciales frente a las NIIF. Academia \& Virtualidad, 9 (2), 108-120.

García, F. y Moya I. (2009). Efecto de las NIIF en el valor bursátil de las empresas españolas. Investigaciones europeas de Dirección y Economía de la empresa, 15 (1), 61-79.

Garza, H. H., Cortez, K. A., Méndez, A. B. y Rodríguez, M. del P. (2017). Efecto en la calidad de la información ante cambios en la normatividad contable: caso aplicado al sector real mexicano. Contaduría y Administración, 62, 746-760.

Gassen, J. y Sellhorn, T. (2006). Applying in Germany: Determinants and Consequences. Recuperado el 2 de octubre de 2017 de: https://papers.ssrn.com/sol3/papers.cfm?abstract_id=906802

Hung, M. y Subramanyam, K. R. (2007). Financial Statement Effects of Adopting International Accounting Standards: The Case of Germany. Review of accounting studies, 12 (4), 623-657.

Instituto Nacional de Contadores Públicos de Colombia (INCP). (2017). Las PyME son la verdadera locomotora económica colombiana. En: https://www.incp.org.co/las-pymes-la-verdadera-locomotora-economica-colombi ana/

International Accounting Standards Board (IASB). (2009). Norma Internacional de Información Financiera (NIIF) para pequeñas y medianas entidades (PyME). London, United Kingdom: IASC Foundation Publications Department.

Jara, L. A., Contreras, H. y Castro, B. (2010). Adopción de IFRS en empresas chilenas del sector eléctrico que cotizan en bolsa. Revista Internacional Legis de Contabilidad \& Auditoría, abril-junio, 131-163.

Lasso, M. G., Vargas, C. A. y Ruano, C. J. (2018). Efecto patrimonial del proceso de convergencia contable en las Pymes colombianas. Estudios Gerenciales, 34 (146), 99-113.

Londoño, L. A. (2015). Impacto financiero en la aplicación de las normas internacionales de información financiera de valoración y registro de la propiedad planta y equipo en los indicadores financieros de las PyME en Colombia. [Trabajo de grado para la maestría en Administración]. Medellín, Colombia: Universidad EAFIT. Recuperado el 17 abril de 2017 de: https://repository.eafit.edu.co/handle/10784/7787\#.WedWb2jWzcs

Lueg, R., Punda, P. y Burkert, M. (2014). Does Transition to IFRS Substantially Affect Key Financial Ratios in Shareholder-Oriented Common Law Regimes? Evidence from the UK. Advances in Accounting, incorporating Advances in International Accounting, 30, 241-250.

Marín, S., Antón, M. y Ortiz, E. (2015). Evidencia empírica de los economistas españoles tras 5 años de aplicación de la reforma contable. Spanish accounting review, 18 (1), 87-98.

Menezes, R. L. y Ciampaglia, P. C. (2017). Full Adoption of IFRSs in Brazil: Earnings Quality and the Cost of Equity capital. Research in International Business and Finance 42, 1057-1073.

Molina, R., Díaz, O. A., Capuñay, J. C. y Casinelli, H. (2014). El proceso de convergencia con las normas internacionales de información financiera en España, Perú y Argentina. Contabilidad y Negocios, 9 (18), 5-26. 
Montoya, A., Montoya, I. y Castellanos, O. (2010). Situación de la competitividad de las Pyme en Colombia: elementos actuales y retos. Agronomía colombiana, 28 (1), 107-117.

Palacios, M. y Martínez, I. (2005). El proceso de armonización contable en Latinoamérica: camino hacia las normas internacionales. R. Cont. Fin., 39, 103-117.

Perafán, H. F. y Benavides, J. (2017). Impact of IFRS on the Quality of Financial Information in the United Kingdom and France: Evidence from a New Perspective. IC 13 (4), 850-878. https://doi.org/10.3926/ic.939.

Perramon, J. y Amat, O. (2006). IFRS Introduction and its Effect on Listed Companies in Spain. Departament of Economics and Business, Universitat Pompeu Fabra, Barcelona. Recuperado el 12 de mayo de 2017 de: http://w ww.econ.upf.edu/docs/papers/downloads/975.pdf

Polo, S. D., Palacios, M. y Martínez, I. (2015). Convergencia de normas contables internacionales entre México y Estados Unidos: evidencia empírica. Innovar, Edición Especial, 21-32.

Quagli, A. y Paoloni, P. (2012). How is the IFRS for SME accepted in the European context? An Analysis of the Homogeneity Among European Countries, Users and Preparers in the European Commission Questionnaire. Advances in Accounting, incorporating Advances in International Accounting 28, 147-156.

Rathke, A. y Santana, V. (2015). Has IFRS improved comparability regarding earnings management in Latin America? In I. Lourenço y M. J. Major (Eds.), Standardization of financial reporting and accounting in Latin American Countries. Hershey: IGI Global.

Rathke, A. A. T., Santana, V. de F., Lourenço, I. M. E. C. y Dalmácio, F. Z. (2016). International Financial Reporting Standards and Earnings Management in Latin America. Revista de administração contemporânea, 20 (3), 368-388.

Rendón, B., Rodríguez, J. y Riascos, P. A. (2013). Análisis del impacto en el capital institucional de las cooperativas de ahorro y crédito frente a la aplicación de las NIIF. Caso cooperativas del Valle del Cauca. Cuadernos de Contabilidad, 14 (36), 881-901.

Robayo, L. E. (2016). Impacto financiero de las normas internacionales de contabilidad NIIF en el patrimonio de las PyME de Cali. [Trabajo de grado para la maestría en Gestión empresarial]. Cali, Colombia: Universidad Libre, seccional Cali. Recuperado el 5 septiembre de 2017 de: http://repository.unilibre.edu.co/bitstream/handle/10 901/10306/RobayoRobayo_2017.pdf?sequence=1

Rodríguez, M. del P., Cortez, K. A., Méndez, A. B. y Garza, H. H. (2017). Does an IFRS Adoption Increase Value Relevance and Earnings Timeliness in Latin America? Emerging Markets Review, 30, 155-168.

Salazar-Baquero, E. E. (2011). Análisis de las implicaciones no financieras de la aplicación de la NIIF para PyME en las medianas entidades en Colombia. Cuadernos de Contabilidad. 12 (30), 211-241.

Salazar-Baquero, E. E. (2013). Efectos de la implementación de la NIIF para las PyME en una mediana empresa ubicada en la ciudad de Bogotá. Cuadernos de Contabilidad. 14 (35), 395-414.

Sarquis, R. W., Luccas, R. G. y Lorenço, I. (2014) Classificação dos Sistemas Contábeis na era IFRS: uma análise dos países da América Latina. XIV Congreso USP Controladoria e Contabilidade: novas perspectivas na pesquisa contábil. Recuperado el 12 septiembre de: http://www.congressousp.fipecafi.org/anais/artigos142014/340.pdf

Silva, A., Pletsch, C., Klann, R., Fasolin, L., Scarpin, J. E. y Major, M. J. (2015). Influence of International Accounting Convergence on the Level of Earnings Management in Both Brazilian and Chilean Companies. In I. Lourenço \& M. J. Major (Ed.), Standardization of Financial Reporting and Accounting in Latin American Countries. Hershey: IGI Global.

Superintendencia de Sociedades de Colombia (SS). (2011). Diagnóstico sobre los impactos contables y financieros de los estándares internacionales de contabilidad e información financiera en las empresas del sector real-fase III. Recuperado el 4 de abril de 2016 de: http://oldsite.supersociedades.gov.co/asuntos-economicos-y-contables/pr ocesos-de-convergencia-niifs/estadistica-de-la-convergencia/Documents/

Superintendencia de Sociedades de Colombia (SS). (2012). Diagnóstico sobre los impactos contables y financieros de los estándares internacionales de contabilidad e información financiera en las empresas del sector real. Recuperado el 4 de abril de 2016 de: http://oldsite.supersociedades.gov.co/asuntos-economicos-y-contables/procesos-de-conve rgencia-niifs/estadistica-de-la-convergencia/Documents/ 
Superintendencia de Sociedades de Colombia (SS). (2015). Análisis de impacto. Recuperado el 4 de abril de 2017 de: https://www.supersociedades.gov.co/delegatura_aec/regulacion_contable/memorias_encuentro_niif/PRE SENTACION\%20ANALISIS\%20DE\%20IMPACTO\%20NIIF\%2017\%20SEPT\%202015.pdf

Uyar, A. y Gungormus, A. H. (2013). Perceptions and knowledge of accounting professionals on IFRS for SMEs: Evidence from Turkey. Accounting regulation, 25, 77-87.

Vásquez, N. (2012). Impacto de las IFRS en los reportes financieros de empresas listadas en la Bolsa Mexicana de Valores. Administración, Finanzas y Economia, 6 (1), 89-107.

Vílchez, P. (2008). La armonización de normas contables en los países de América. Contabilidad y Negocios, 3 (5), 5-10.

Yáñez, V., Pilar, F. e Inostrosa, C. (2010). Impacto de las IFRS en la valoración de empresas: evidencia para una muestra de empresas chilenas cotizadas. Activos, 15, 135-162.

Licencia Creative Commons CC BY 4.0

Para citar este artículo: Ruano-Delgado, C. J., Vargas-Sierra, C. A. y Lasso-Marmolejo, G. (2018). Convergencia contable de las PyME colombianas. Cuadernos de Contabilidad, 19(47), 1-23. https://doi.o $\mathrm{rg} / 10.11144 /$ Javeriana.cc19-47.ccpc 